\title{
A MEDIAÇÃO COMO CATEGORIA METODOLÓGICA NA PESQUISA EDUCACIONAL
}

\author{
Rosemary Lopes Soares da Silva
}

Universidade do Estado do Rio de Janeiro, Brasil. roselsoares@yahoo.com.br

\begin{abstract}
Resumo. O artigo analisa a categoria da mediação no materialismo histórico dialético a partir dos estudos de Saviani (2015) e Ciavatta (2014), problematizado as diferentes abordagens desta categoria na pesquisa social, e, em particular, na pesquisa educacional. O percurso que se segue será o de apresentar as diferentes perspectivas das mediações no método dialético e como cada uma contribui metodologicamente para a apreensão de um objeto científico. Nesse sentido, tem-se como objetivo discutir a categoria da mediação como a busca pelos nexos e as relações que se entrelaçam e que explicam como determinada realidade se materializa, e por quais mediações uma dada realidade se configurou. Apresenta um estudo das mediações para a implementação da reforma do ensino médio, materializada na Lei 13415/2017, como a expressão dos passos de uma investigação sobre a uma política educacional. Finaliza com o argumento de que a categoria da mediação, como parte de um método de investigação, embora seja aplicada em diferentes perspectivas pelos autores, há uma unidade entre essas diferentes abordagens, ao considerar que esta categoria é o processo pelo qual é possível explicitar as relações entre a particularidade e a totalidade dos fenômenos estudados na pesquisa social para a apreensão do real.
\end{abstract}

Palavras-chave: Dialética; Mediação; Particularidade; Totalidade.

\section{MEDIATION AS A METHODOLOGICAL CATEGORY IN EDUCATIONAL RESEARCH}

\begin{abstract}
The article analyzes the category of mediation in dialectical historical materialism from the studies of Saviani (2015) and Ciavatta (2014), problematizing the different approaches of this category in social research, and, in particular, in educational research. The course that follows will be to present the different perspectives of mediations in the dialectical method and how each methodologically contributes to the apprehension of a scientific object In this sense, the objective is to discuss the category of mediation as the search for nexuses and the relationships that intertwine and that explain how a given reality materializes, and through which mediations a given reality was configured It presents a study of the mediations for the implementation of the reform of high school, materialized in Law 13415 / 2017, as the expression of the steps of an investigation on an educational policy It ends with the argument that the mediation category, as part of an investigation method, although it is applied in different perspectives by the authors, there is a unity between these different approaches, considering that this category is the process by which it is possible to make explicit the relations between the particularity and the totality of the phenomena studied in social research for the apprehension of the real.
\end{abstract}

Keywords: Dialectic; Mediation; Particularity; Totality.

\section{INTRODUÇÃO}

Iniciamos a nossa discussão apresentando a categoria da mediação como parte de um processo de investigação qualitativa, especialmente usada no campo da pesquisa social, situada dentro do método histórico-dialético, através dos autores que foram eleitos como sendo as referências, tendo os seus estudos se debruçado em explicitarem sobre o uso da categoria mediação para a compreensão de uma dada realidade, isto é, como questão metodológica da construção do objeto científico. A compreensão de que o método não se separa do seu objeto; ao contrário, é ele que o constitui (Ciavatta, 2014), não implica 
necessariamente que dentro do mesmo método histórico dialético, a categoria da mediação tenha o mesmo uso.

Em seguida, discorremos sobre a dialética como expressão do movimento da realidade Nesse sentido, discutiremos que o método dialético em Marx, também denominado na literatura como método histórico-dialético, ou ainda, materialismo histórico-dialético, que é composto por categorias diferentes da lógica formal aristotélica, quando na construção do conhecimento, a investigação da realidade se faz na relação entre os raciocínios indutivos e dedutivos, em que o processo de conhecimento tem como ponto de chegada e de partida o campo empírico. A lógica dialética, por sua vez, na construção do conhecimento, investiga o movimento da realidade, "o processo de conhecimento em seu conjunto é um momento do processo concreto (o real-concreto) Processo, porque o concreto não é o dado (o empírico), mas uma totalidade articulada, construída e em construção" (Saviani, 2015, p. 28).

Encaminharemos para as conclusões, problematizando os diferentes usos da categoria mediação tendo como referência o método histórico-dialético, em Saviani (2015) e Ciavatta (2014), para o estudo de um mesmo tema, a pesquisa da política educacional no Brasil. Em síntese, afirmaríamos que, a mediação como uma categoria que busca a explicitação dos processos e dos nexos entre o fenômeno estudado e a totalidade social, no qual está inserida, é por ela que se pode transitar para captar o movimento desde o campo empírico à formulação das categorias no campo do concreto real (Kosik, 2011). Portanto, são os estudos das mediações, que permitem a apreensão do real, seja pelas determinações mais simples ao evidenciar as particularidades históricas, a duração, o espaço, o movimento, seja pelos conceitos e categorias que constituíram o estudo do objeto científico.

\section{A DIALÉTICA NA ANÁLISE DA PESQUISA EDUCACIONAL}

A dialética da totalidade é a referência que tem como base Ciavatta (2014), para afirmar em seus estudos, a partir de (Kosik, 2011), que se trata de uma teoria da realidade em que seres humanos e objetos existem em relação, e nunca isolados, como alguns processos analíticos podem fazer crer. É a partir da dialética da totalidade que um objeto é estudado com a finalidade de concebê-lo na totalidade das relações que o determinam, sejam elas de nível econômico, social, cultural. Ao afirmar que esta lógica de construção do objeto do científico é a lógica da construção histórica, portanto, não ignora a história. Nesta concepção, o objeto singular é visto a partir de sua gênese nos processos sociais mais amplos, reconstrui-lo a partir de uma determinada realidade que é sempre complexa, aberta 
a transformações sob a ação dos sujeitos - isto é, a história como método. Entender a história como método e como processo é também uma questão política, há neste processo implícita ou explicitamente, posições político-ideológicas de exaltação, de defesa ou de condenação a homens, ações e acontecimentos. É Marx quem vai explicitar os elementos políticos e ideológicos da história e concebê-la como o processo da vida real dos homens e como a ciência deste processo (Ciavatta, 2014).

Apoia-se nos estudos do historiador Braudel (1982), ao incorporar as mediações históricas, a teoria dos tempos múltiplos, de inspiração das teorias das ciências sociais, para analisar a realidade na perspectiva da dialética da duração. Assim, Braudel fala da história, e do tempo da história, que tem basicamente três níveis: "a curta duração dos acontecimentos; a média duração da conjuntura (por sua vez com múltiplos tempos e ritmos); a longa duração das estruturas, além da longuíssima duração da geo-história" (Ciavatta, 2014, p. 203).

Sobre a lógica dialética, os estudos de Saviani (2015), com base em Marx (1973), vão afirmar que é com a dialética que supera-se a oposição entre indução e dedução, os dois raciocínios serão incorporados numa síntese superior compreensiva do método do conhecimento científico. Nessa perspectiva, a produção do conhecimento científico segue em direção a um movimento global que compreende dois momentos. No momento inicial, parte-se do empírico, isto é, do objeto tal como se apresenta à observação imediata, o objeto é captado numa visão caótica, isto é, não se tem clareza do modo como ele está constituído. Aparece, pois, sob a forma de um todo confuso, portanto, como um problema que precisa ser resolvido. Em seguida pela mediação da análise, chega-se aos conceitos e abstrações, e no momento seguinte, à síntese. O objeto científico agora entendido não mais como "a representação caótica de um todo", mas como "uma rica totalidade de determinações e de relações numerosas" (Saviani, 2015, p. 08).

O método marxiano tem como premissa que o concreto é concreto por ser a síntese de múltiplas determinações, logo, unidade na diversidade. É por isso que o concreto é para o pensamento um processo de síntese, um resultado, e não um ponto de partida (Marx, 1977). Nesta perspectiva, no pensamento marxiano, existe uma lógica interna entre a história, a sociedade e a economia que são apresentadas como um processo com unidade indissolúvel. A diferença fundamental entre a lógica formal e a dialética é a importância dada a categoria contradição, que é negada pela lógica formal, como uma impossibilidade. 
O método marxiano afirma a importância da categoria contradição e com as demais categorias: reciprocidade, mediação e historicidade detalham o método da crítica da economia política desenvolvido por Marx (Ciavatta, 2014).

É por meio da dialética como a lógica da produção do conhecimento científico na pesquisa educacional, especificamente, na pesquisa sobre uma determinada política pública, que busca-se captar o movimento histórico, as relações e as tendências do objeto investigado. A ideia de Movimento é compreendido a partir de Cheptulin (2004, p. 165) "como a passagem constante da matéria de um estado estável a outro, com o aparecimento de novas formações que se substituem". A questão que se coloca é a de saber qual é a tendência de todas essas transformações, qual é o sentido do movimento e o que aparece no lugar das formações materiais que desapareceram.

Nesta perspectiva, o estudo da política educacional, torna-se complexo, na medida em que se embasa pela lógica dialética, ou seja, do movimento que a remete como objeto de estudo à sua totalidade histórica, e às relações que aí se estabelecem. O desafio para o pesquisador está em buscar a aproximação com a realidade concreta "a partir dos filtros dos conceitos e das categorias, isto é, buscar captar os elementos mais concretos, as objetivações reais que explicam essa totalidade não como uma noção genérica, mas como um conteúdo de natureza histórico-social” (Ciavatta, 2014, p. 214).

A política educacional abordada neste texto trata da reforma do ensino médio, materializada pela Lei 13415/2017, em que o estudo realizado esteve interessado, metodologicamente, em captar quais os nexos históricos e conceituais implicados na implementação desta legislação no Brasil.

Nesta perspectiva, a síntese apresentada possibilita explicitar as mediações, os acontecimentos, as relações - entre a particularidade e totalidade social - que estiveram em movimento para implementar novos currículos sob a égide da flexibilização curricular e da possibilidade de oferecer itinerários formativos diversificados, a partir dos quais, os estudantes poderão realizar as suas escolhas de percursos escolares para a conclusão da etapa da educação da educação básica. 


\section{MEDIAÇÃO COMO CATEGORIA METODOLÓGICA: CAPTAR AS DETERMINAÇÕES HISTÓRICAS, OS CONCEITOS E AS CATEGORIAS ANALÍTICAS}

A mediação como categoria metodológica em Ciavatta (2014, p. 216) "é uma visão historicizada do objeto singular, cujo conhecimento deve ser buscado nas suas determinações mais gerais, nos seus universais, assim como situada no tempo e no espaço, isto é, na contextualização histórica". Nos seus estudos ela buscou evidenciar a questão teórico-metodológica das mediações e os diferentes usos do termo mediação, em diferentes abordagens epistemológicas da produção do conhecimento, apoiada nas análises de autores do campo da metodologia da pesquisa científica. Buscou reafirmar que metodologicamente o conceito de mediação permite a passagem da visão do objeto empírico, singular à luz dos conceitos gerais, dos universais que constituem a linguagem, as formas de comunicação e toda a gama de noções, categorias e conceitos que pensamos:

As mediações não são apenas meios, como frequentemente o termo é usado na linguagem comum e também nos discursos acadêmicos. Os meios são instrumentos, são elos, pontos de ligação Vistos sob o conceito de mediação, os objetos revelam-se como processos sociais complexos, com significados diversos, dependendo de sujeitos atuantes e da dinâmica dos fenômenos envolvidos. É no campo da particularidade que se situa as mediações É o campo da história, do conhecimento dos objetos em determinado tempo e lugar, como produções humanas.

(...) A categoria mediação permite trabalhar com a singularidade empírica, com o local, com o tempo breve dos acontecimentos, não como objetos individuais, isolados, mas em sua articulação com o contexto, com a cultura, com o mundo do qual fazem parte. (Ciavatta, 2014, pp 227-228)

Entendemos que no processo de investigação de um dado fenômeno na pesquisa social, o processo de desvelamento dos acontecimentos históricos das mediações permite fazer a construção do objeto científico com a totalidade social. De acordo com Ciavatta (2014), essa construção não é entendida como uma racionalização ou modelo explicativo, mas um conjunto dinâmico de relações que passam necessariamente, pela ação de sujeitos sociais. O conceito de totalidade social remete a concepção de totalidades - que são tão heterogêneas e tão diversificadas quanto os aspectos da realidade -, portanto, tem um referente histórico, material, social, moral ou afetivo de acordo com as relações que constituem determinada totalidade. 
Embora o uso do termo totalidade dê margem para que haja distorções, como a aproximação com o termo totalitarismo, outro equívoco é relacionar o termo ao sentido de "tudo", que inviabiliza o processo de conhecimento. No sentido marxiano, "() a totalidade é um conjunto de fatos articulados ou o contexto de um objeto com suas múltiplas relações, ou, ainda, um todo estruturado que se desenvolve e se cria como produção social do homem" (Ciavatta, 2014, p. 195). Considerando a centralidade da categoria de "mediação" na concepção dialética, e sua reformulação em bases materialistas a partir dos estudos de Marx, a mediação é uma categoria central da dialética que, em articulação com a "ação recíproca", compõe com a "totalidade" e a "contradição", o arcabouço categorial básico da concepção dialética da realidade e do conhecimento. "A construção do pensamento ocorre, pois, da seguinte forma: parte-se do empírico, passa-se pelo abstrato e chega-se ao concreto. Ou seja: a passagem do empírico ao concreto se dá pela mediação do abstrato" Saviani (2015, p. 26). A construção do conhecimento na lógica dialética se dá por um processo diferente da lógica formal, é preciso ter presente o caráter dialético da teoria, pois não se trata de uma relação mecânica entre os passos do método que determinaria o que vem primeiro e o que vem depois. A dialética é a lógica dos conteúdos, enquanto a lógica formal se ocupa com as formas.

O processo de conhecimento em seu conjunto é um momento do processo concreto (o real-concreto) Processo, porque o concreto não é o dado (o empírico), mas uma totalidade articulada, construída e em construção. O concreto, ao ser apropriado pelo homem sob a forma de conhecimento, é a expressão, no pensamento, das leis que governam o real. A lógica dialética se caracteriza, pois, pela construção de categorias saturadas de concreto. Pode, pois, ser denominada a lógica dos conteúdos, por oposição à lógica formal que é, como o nome indica, a lógica das formas (Saviani, 2015, p. 28).

Tendo como referência a relação do homem com a natureza a partir da obra de Marx, a categoria trabalho tem a centralidade como explicativa das transformações que passam homem e natureza quando estão em relação. Pelo trabalho o homem "() defronta-se com a natureza como uma de suas forces. Põe em movimento as forças naturais de seu corpo, braços e pernas, cabeça e mãos, a fim de apropriar-se dos recursos da natureza, imprimindo-Ihes forma útil à vida humana" (Marx, 1968, p. 202) Portanto, para Saviani a categoria mediação também ganha centralidade explicativa, uma vez que o trabalho é o meio pelo qual as transformações sociais acontecem.

A centralidade da categoria de mediação deriva diretamente da centralidade do trabalho, que é o processo pelo qual o homem, destacando-se da natureza entra em contradição com ela necessitando negá-la para afirmar sua humanidade. Dessa forma, um ser natural, o homem, torna-se obrigado, para 
existir, a produzir sua própria vida agindo sobre a natureza e transformando-a. Nessa relação metabólica a natureza se apresenta ao mesmo tempo como o meio no qual o homem vive e como o meio pelo qual ele vive. Com a liberação das mãos e o ato de manipulação, isto é, o trabalho sobre a natureza, emerge também a consciência, ou seja, a percepção do uso de certos meios para se chegar a determinado resultado. Diante dos objetos (ob-jecti), o homem define-se como projeto (pro-jectus, lançado adiante), (Saviani, 2015, pp. 33-34).

Para se tornar atual à sua época o indivíduo necessita se apropriar do conjunto das objetivações humanas que configuram o contexto da atualidade. Na pesquisa social não é diferente, a apropriação do conjunto das objetivações que deram materialidade a uma determinada realidade é captada pelo estudo das mediações, que em Saviani (2015, p. 36), são as práticas sociais, isto é, "ter presente o modo como está estruturada a sociedade atual, conhecê-la o mais profundamente possível". Conhecer implica, captar o movimento que nos permite entender como nasceu essa sociedade; de onde ela surgiu; como se encontra estruturada; quais as contradições que a movem definindo as tendências de seu desenvolvimento e apontando para as possibilidades de sua transformação numa nova forma de ordem superior; acesso aos instrumentos por meio dos quais os diferentes aspectos que compõem a estrutura social serão progressivamente elaborados na forma de superestrutura em sua consciência.

A mediação se materializa pela instrumentação, entendida como a apropriação dos instrumentos teóricos e práticos necessários ao equacionamento dos problemas detectados na prática social. "Pela mediação dos instrumentos teóricos e práticos devidamente apropriados manifesta-se o momento da expressão elaborada da nova forma de entendimento da prática social a que se ascendeu" (Saviani, 2015, p. 37).

Contextualizar a categoria da mediação como processo metodológico para a realização da pesquisa social, é não perder de vista que a construção do conhecimento é guiado pela lógica dialética, na qual o sujeito que pesquisa está intrinsecamente incluído na sociedade e nas práticas sociais nas quais estão inseridos o objeto da sua pesquisa, isto é, o sujeito não está fora da ação e agindo distante dela (a pesquisa e o seu objeto),

() não se age primeiro, depois se reflete e se estuda, em seguida se reorganiza a ação para, por fim, agir novamente" o pesquisador está dentro da ação. Trata-se de um processo em que esses elementos se interpenetram desenrolando o fio da existência humana na sua totalidade (Saviani, 2015, p. 39). 
Citando Marx (1973), é pela mediação da análise que se chega aos conceitos, as abstrações e as determinações mais simples, que constituem no seu conjunto, os nexos explicativos necessários ao objeto da pesquisa social, especifica:

O movimento global do conhecimento, compreende dois momentos. Pelo primeiro parte-se do empírico, isto é, do objeto tal como se apresenta à observação imediata, tal como é figurado na intuição e, pela mediação da análise, chega-se aos conceitos, às abstrações, às determinações mais simples. Uma vez atingido esse ponto, faz-se necessário percorrer o caminho inverso (segundo momento) chegando, pela mediação da síntese, de novo ao objeto, agora entendido não mais como "a representação caótica de um todo", mas como "uma rica totalidade de determinações e de relações numerosas" (Saviani, 2015, p. 39).

Consideramos que, para tratar da pesquisa educacional contemporânea no Brasil, especificamente, sobre o estudo da política pública para a educação básica, se faz crucial compreendê-la em suas múltiplas determinações, por dentro das relações econômicas internacionais, dado que tais políticas concretizam uma agenda estruturada pelos organismos internacionais a exemplo do Banco Mundial e da Organização para a Cooperação e Desenvolvimento Econômico ou Económico - OCDE - especialmente, para os países de capitalismo dependente da América Latina e África, que recorrem aos empréstimos internacionais, para tocarem suas políticas internas no mais diversos setores e na educação em particular. Além disto, o Brasil é signatário de convenções internacionais que exercem pressões para a implementação de políticas que seguem as determinações de algum padrão internacional.

O desdobramento da pesquisa buscou captar pelas mediações, dos estudos dos documentos legais, oficiais, nacionais, internacionais, bem como, com a revisão da literatura dos estudos de intelectuais brasileiros - pesquisadores do campo das políticas públicas educacionais na relação entre trabalho e educação, - tais como, Ramos (2017); Kuenzer (2017); Evangelista (2012); Shiroma (2004) Pelo método dialético, se realizou o estudo da política educacional, no sentido de captar por quais mediações, isto é, as determinações mais simples, o movimento, o espaço - tempo, os conceitos e as categorias que explicam os interesses contraditórios pela reforma da educação básica no Brasil em que se materializou a reforma educacional que originou a Lei 13415/2017 conhecida como a Reforma do Ensino Médio. 


\section{PESQUISA EDUCACIONAL SOBRE A REFORMA DO ENSINO MÉDIO: MEDIAÇÕES E CONTRADIÇÕES DA LEI 13415/2017}

A Reforma do Ensino Médio, teve seu início com o Projeto de Lei no 6840 de 2013, que resultou na Medida Provisória no 746, de 22 de setembro de 2016, materializada na Lei 13415, de 16 de fevereiro de 2017, que estabeleceu as novas diretrizes e bases para o ensino médio. Literalmente, a mudança institui a flexibilização curricular por meio da sua organização em itinerários formatives. A implementação da Lei 13415/2017, sobre a Base Nacional Comum Curricular do Ensino Médio, foi regulamentada pelas Resoluções 03/2018 e 04/2018, que respectivamente: "Atualiza as Diretrizes Curriculares Nacionais para o Ensino Médio" e "Institui a Base Nacional Comum Curricular na Etapa do Ensino Médio (BNCC-EM)". Entretanto, recorremos ao estudo e uma breve retomada do contexto histórico que a antecede, isto é, do movimento das política públicas para a reforma do Ensino Médio, com a finalidade de compreender como se configura a atual proposta de flexibilização curricular e da organização dos currículos por itinerários formatives.

O movimento iniciado pela reivindicação de uma Base Nacional Comum Curricular - BNCC, durante a realização da conferencia nacional da educação - CONAE, em 2010, no contexto das discussões para a elaboração do Plano Nacional de Educação - PNE, aprovado pela Lei no 13005 , de 25 de junho de 2014, constitui-se em documento fundamental - com 20 Metas e as respectivas Estratégias - para as políticas públicas, que tem como principal finalidade assegurar um sistema educacional capaz de concretizar o direito à educação em sua integralidade, dissolvendo as barreiras para o acesso e a permanência, reduzindo as desigualdades, promovendo os direitos humanos e garantindo a formação para o trabalho e para o exercício autônomo da cidadania.

Especificamente, a Meta 3 do PNE que dispõe sobre o Ensino Médio, na Estratégia 31, explicita sobre a necessidade da renovação do ensino médio, a saber:

Meta 3: universalizar, até 2016, o atendimento escolar para toda a população de quinze a dezessete anos e elevar, até o final do período de vigência deste PNE, a taxa líquida de matrículas no ensino médio para oitenta e cinco por cento

Estratégias: 31 institucionalizar programa nacional de renovação do ensino médio, a fim de incentivar práticas pedagógicas com abordagens interdisciplinares estruturadas pela relação entre teoria e prática, por meio de currículos escolares que organizem, de maneira flexível e diversificada, conteúdos obrigatórios e eletivos articulados em dimensões como ciência, trabalho, linguagens, tecnologia, cultura e esporte, garantindo-se a aquisição de equipamentos e laboratórios, a produção de material didático 
específico, a formação continuada de professores e a articulação com instituições acadêmicas, esportivas e culturais. (Brasil, 2014, p. 52)

Os estudos de Shiroma (2004), vem mostrando que desde os anos de 1990 a conjuntura política com as reformas administrativas trouxeram consigo expressões como "qualidade total", "modernização do ensino", "adequação ao mercado de trabalho", "competitividade", "eficiência e produtividade", "empregabilidade e modularização", todas originadas na nova ideologia neoliberal. Atribuiu-se à educação a responsabilidade de aumentar a competitividade dos indivíduos e do país, na defesa de que para se tornar um cidadão do século XXI e incluir-se como país desenvolvido, seria imperativo ter uma população capaz de dominar os códigos da modernidade.

No contexto atual, que se inicia a partir dos anos de 2017, a legislação para o ensino médio instituída pela Lei 13415/2017, apresenta mudanças significativas na última etapa da educação básica com implicações para carga horária e, consequentemente, na organização e delimitação dos conteúdos curriculares da base nacional comum, que repercutem nas matrizes curriculares como um todo e na oferta de cursos e na formação dos estudantes da educação profissional integrada, sobretudo pela delimitação da quantidade máxima de 1800 horas que afeta diretamente a formação integrada da etapa propedêutica.

Para além das mudanças que vêm sendo discutidas na organização do ensino médio regular no Brasil, destacam-se três que merecem reflexões mais aprofundadas sobre o que está posto na reforma:

a) a questão que envolve o currículo do ensino médio, que volta a ser organizado por competências gerais e as respectivas habilidades de cada área do conhecimento que estará na composição de cada itinerário formativo;

b) a transformação da Educação Profissional em um itinerário formativo dado que pode se realizar em instituições escolares e/ou outras instituições não escolares1, conforme explicitado na Portaria no 1432/2018, ao considerar as modalidades presencial ou à distância, seus professores prescindem de formação científica e pedagógica por meio do dispositivo do "notório saber;

c) a mudança dos referenciais teóricos e metodológicos para a formação do estudante da rede pública que, além de instituir a flexibilização curricular, com apenas a obrigatoriedade para cursar mais de um itinerário, e não mais as quatro Áreas do Conhecimento, estabelece também, uma carga horária

\footnotetext{
${ }^{1}$ Portaria no 1.432, de 28 de dezembro de 2018, publicada em 05/04/2019. Estabelece os referenciais para elaboração dos itinerários formativos conforme preveem as Diretrizes Nacionais do Ensino Médio, § 8odo art. 36, que "[...] a oferta de formação técnica e profissional poderá ser realizada na própria instituição ou em parceria com outras instituições",
} 
máxima ${ }^{2}$ de ensino, em vez de uma carga horária mínima e dispõe como a obrigatoriedade de oferta nos três anos da etapa os componentes curriculares de Língua Portuguesa e Matemática.

Historicamente, na legislação educacional brasileira, não há registro de estabelecimento do máximo de carga horária destinada aos componentes curriculares que o estudante deverá estudar, no entanto, o §5ำ do Art, 3ำ da Lei № 13415/2017, estabelece como máxima a carga horárias de 1800 horas para a Formação Geral - BNCC, e 1200 horas como carga horária mínima para a parte diversificada, totalizando uma carga horária máxima de 3000 horas para o ensino médio regular nos itinerários formatives.

A Resolução 04/2018 ao estabelecer a Base Nacional Comum Curricular na Etapa do Ensino Médio - BNCC (EM), estabelece que, no processo de construção de suas propostas pedagógicas, atendidos todos os direitos e objetivos de aprendizagem instituídos na BNCC$E M$, as instituições escolares, redes de escolas e seus respectivos sistemas de ensino poderão adotar formas de organização e propostas de progressão que julgarem necessárias. No Art $2^{\circ}$ da mesma resolução informa que “() as aprendizagens essenciais são definidas como conhecimentos, habilidades, atitudes, valores e a capacidade de os mobilizar, articular e integrar, expressando-se em competências". No Art 10, explicita que a formação geral básica tem a BNCC-EM, como referência obrigatória, sendo composta pelas previstas competências e habilidades.

Os estudos de Kuenzer (2017, p 339) sobre a reforma atual do ensino médio vão afirmar que, dada a duração de apenas 1800 horas, a ser complementada pelos estudos em itinerários formativos flexíveis, ou seja, a formação geral se dará também por uma parte que se chama de flexibilização curricular, se relaciona com o que já propunha o Banco Mundial como política para os países pobres desde a década de 1990: a integração entre teoria e prática se dará ao longo das trajetórias de trabalho, secundarizando a formação escolar, tanto de caráter geral como professional.

Para a autora, as mudanças nas políticas públicas estão em consonância com as demandas do mercado, e estimulam cada vez mais, a utilização das novas tecnologias de informação e comunicação, que visam implementar outra qualidade à aprendizagem, para atender ao objetivo da nova pedagogia para formar subjetividades flexíveis, aproximando-a dos novos

\footnotetext{
${ }^{2}$ Lei $13.415 / 2017$. Art. 3ำ $5^{\circ}$ A carga horária destinada ao cumprimento da Base Nacional Comum Curricular não poderá ser superior a mil e oitocentas horas do total da carga horária do ensino médio, de acordo com a definição dos sistemas de Ensino.
} 
padrões de comportamento social e das práticas laborais da sociedade informatizada, das subjetividades que se relacionem, produzam e consumam em uma sociedade cuja base técnica, para mover o mercado, é a microeletrônica (Kuenzer, 2017).

Os estudos de Ramos (2018), sinalizam as influências que se manifestam do alinhamento das políticas educacionais no Brasil com políticas internacionais equivalentes, como é o caso do Programa Internacional de Avaliação de Estudantes (PISA) e pelos mecanismos de diálogo e assessoramento de organismos internacionais nas políticas de avaliação em larga escala da educação básica no Brasil, a exemplo do modo como opera o Sistema de Avaliação da Educação Básica no Brasil (SAEB), com aplicação de provas que visam aferir a proficiência dos estudantes da educação básica, no domínio dos conteúdos de língua portuguesa e matemática. Os resultados da avaliação externa do SAEB nos sistemas de ensino, nos âmbitos estadual e municipal, são os indicadores para as alterações na legislação educacional, com o expediente de novas diretrizes, resoluções, decretos e alterações na Lei de Diretrizes e Bases da Educação - LDB 9394/96, texto Ramos (2018), analisou em que medida as políticas de avaliação em larga escala da educação básica expressam a influência da globalização e do neoliberalismo no campo da educação em nosso país. Ainda que as influências do movimento global do capital e das políticas internacionais, que têm os Organismos Internacionais como seus representantes não destituam completamente os Estados nacionais de sua autonomia, configuram-se ações de alinhamento com seus princípios.

A política educacional materializada na Lei 13415/2017 revela que a principal contradição desta política é que com o argumento de elevar a aprendizagem dos estudos e assegurar o direito a aprendizagem e elevação da qualidade da educação que é medida pelo índices de proficiência nas avaliações externas, ela o faz pela redução da carga horária de estudos da Base Nacional Comum Curricular - BNCC, tornando obrigatórios os estudos dos componentes curriculares de Língua Portuguesa e Matemática nas três séries do Ensino Médio, reduzindo a carga horária das demais áreas do conhecimento e tornando desobrigatório o seu estudo nos três anos. Além disso, eleva a carga horária da parte diversificada do currículo, que é composto por componentes curriculares flexíveis, optativos, eletivos, com conteúdos diversos daqueles estudados nos componentes das áreas científicas da BNCC Ramos (2018) conclui que, com o argumento de diminuírem as desigualdades e as diferenças nos desempenhos dos estudantes pelos resultados das avaliações externas, reduz-se o currículo da Base Nacional e, dessa forma, diminui-se as 
exigências destes estudos para elevar a média de desempenho. Eleva-se o desempenho pela redução do conhecimento geral e pelo reforço dos conteúdos específicos que interessam nos exames realizados pelas avaliações externas.

\section{CONCLUSÕES}

O estudo da mediação como categoria metodológica da pesquisa educacional requer situar as bases da intermediação entre a teoria do conhecimento com a qual dialoga com o objeto estudado. A questão do método e a construção do objeto de pesquisa implica a questão epistemológica (Ciavatta, 2014). Demonstramos neste trabalho, que os estudos de Ciavatta (2014) e Saviani (2015) abordam sob diferentes perspectivas o uso metodológico da mediação. Os estudos aprofundados que realizamos no Grupo These ${ }^{3}$ sobre esta categoria, a partir da literatura selecionada para este trabalho, tendo como referência os dois autores, nos permitem afirmar que, em Ciavatta as mediações são alcançadas no processo de conhecimento do objeto pesquisado, isto é, a ênfase recai sobre a investigação. É pela investigação, por meio do processo, que chegamos às mediações históricas, a partir das determinações mais simples.

É um processo interno de busca pelas determinações do real no plano do pensamento, a elaboração do conceito corresponde ao real Não existe concreto pensado sem conceito. Em Saviani, as mediações se dão pelos conceitos, os conceitos são apropriados para fins analíticos, a ênfase nas mediações recai sobre um processo que é formativo que transita do estudo da prática social (empírica; como ponto de partida) à prática social (concreto pensado; como ponto de chegada para o real).

Neste sentido, a pesquisa em política educacional, especificamente, a política educacional implementada pela Lei 13415/2017, ao buscar responder por quais mediações relacionam a particularidade com a totalidade histórica, vai ao encontro de saber, como se movimenta a realidade, como se materializa as determinações mais simples a partir dos fenômenos aparentes, quais sejam "elevar os indicadores da aprendizagem e proficiência de duas áreas do currículo: português e matemática", com as determinações históricas "as relações entre o mundo do trabalho e da educação que favoreçam a reprodução do capitalismo nas esferas

\footnotetext{
${ }^{3}$ Grupo These é o grupo interinstitucional cadastrado no Cnpq desde 2005, composto por pesquisadores da UERJ/UFF e FIOCRUZ que se dedicam as pesquisas e aos estudos sobre Trabalho, Educação e Saúde. Como egressa do doutorado do PPFH/UERJ, participo deste grupo de pesquisa.
} 
econômicas e sociais", isto é, as implicações com os conceitos de neoliberalismo e globalização no campo da educação.

O estudo de uma política educacional preocupada em investigar metodologicamente por quais as mediações históricas determinada política se materializou, o faz, como uma síntese teórico-metodológica, que expressa a historicidade dos acontecimentos, dos sujeitos e das estruturas sociais da gênese e das disputas na formação dos trabalhadores de uma relação entre o trabalho e a educação Ciavatta (2009).

Entendemos que a mediação como metodologia de um processo de pesquisa, se relaciona com a lógica dialética na medida em que estuda o objeto no movimento dialético para captar interna e externamente as determinações de um fenômeno, e relacioná-lo nas suas particularidades com a totalidade social, das relações que o engendram.

Partindo da sua aparência mais simples, e avançando para compreender e explicar a determinações mais gerais que tem a sua raiz histórica. A explicação do fenômeno e a construção dele como objeto científico, sob o critério de validade de um método científico, dependem das determinações externas: os conceitos e as categorias que são aplicadas na sua análise e na validação da construção das sínteses.

Os estudiosos do campo das políticas educacionais apresentam as concepções teóricas e as mediações conceituais, que constituem as categorias para a análise do fenômeno neste estudo, especificamente, para a análise da política educacional materializada na legislação 13415/2017, trabalhamos com as categorias flexibilização produtiva, flexibilização curricular, contradição.

\section{REFERÊNCIAS}

Brasil Lei 13415/2017 (2017). institui a Política de Fomento à Implementação de Escolas de Ensino Médio em Tempo Integral Brasília: Ministério da Educação.

Brasil Resolução nº 3, de 21 de novembro de 2018 Atualiza as Diretrizes Curriculares Nacionais para o Ensino Médio Disponivel em: http://novoensinomediomecgovbr/resources/downloads/pdf/dcnempdf.

Brasil Resolução no 4, de 17 de dezembro de 2018 Institui a Base Nacional Comum Curricular na Etapa do Ensino Médio (BNCC-EM), como etapa final da Educação Básica, nos termos do artigo 35 da LDB, completando o conjunto constituído pela BNCC da Educação Infantil e do Ensino Fundamental, com base na Resolução CNE/CP no 2/2017, fundamentada no Parecer CNE/CP no 15/2017 Disponível em: http://portalmecgovbr/docman/dezembro-2018-pdf/104101-rcp004-18/file.

Cheptulin, A. A. (2004). Dialética materialista: categorias e leis da dialética. São Paulo: Alfa- ómega. 
Ciavatta, M. (2009). Mediações históricas de trabalho e educação: gênese e disputas na formação do trabalhador. Rio de Janeiro: Lamparina.

Ciavatta, M. O. (2014). Conhecimento histórico e o problema teórico-metodologico das mediações. In: G. Frigotto \& M. Ciavatta (Orgs.), Teoria e educação no labirinto do capital (pp. 192-229). São Paulo: Ep Expressão Popular.

Evangelista, O. (2012). Políticas públicas educacionais contemporâneas, formação docente e impactos na escola XVI ENDIPE- Encontro Nacional de Didática e Práticas de Ensino, UNICAMP: Campinas.

Kosik, K. (2011). Dialética do concreto. São Paulo: Paz e Terra.

Kuenzer, A. (2017). Trabalho e escola: a flexibilização do ensino médio no contexto do regime de acumulação flexível. Rev Educ Soc, 38(139), 331-354.

Liguori, G, \& Voza, P. (2017). Dicionário Gramsciano, (1926-1937). São Paulo: Boitempo.

Marx, K. (1977). Contribuição para a critica da Economia Política. São Paulo: Martins Fontes.

Ramos, M. N. Ensino médio na rede federal e nas redes estaduais: por que os estudantes alcançam resultados diferentes nas avaliações de larga escala? Holos, Rio Grande do Norte, v. 2, p. 449-59, 2018. https://doi.org/10.15628/holos.2018.6976

Saviani, D. O. (2015). Conceito dialético de mediação na pedagogia histórico-crítica em intermediação com a psicologia histórico-cultural. Germinal: Marxismo e Educação em Debate Salvador, 7(1), 26-43.

Saviani, D. (2019). Pedagogia histórico-critica: novas aproximações. Campinas: São Paulo: Autores Associados.

Shiroma, E. O; Moraes, C. M., \& Evangelista, O. (2004). Política educacional. Rio de Janeiro: DP\&A. 